\title{
RETURNING TO THE CLASSROOM DURING THE COVID-19 PANDEMIC A PROCESS THAT IMPLIES KNOWLEDGE, RESPONSIBILITY AND COMMITMENT
}

\author{
Ignacio Montenegro \\ Colombia
}

\begin{abstract}
The return to the classroom in times of COVID-19 is inevitable. The purpose of this article is to help the authorities and educational communities think about the progressive and safe return for students. The main foundation is life as a core value. Therefore, the dynamics of the pandemic is the main factor to take into account to initiate the return. This return implies informed, consensual and responsible decisions on the part of authorities, directives, teachers, parents and students. The objective of the return is to offer an education of quality and relevance to the students. A systematic process of diagnostic evaluation, planning, preparation, piloting, and progressive return is required to guarantee safe return to classrooms.
\end{abstract}

\section{KEYWORDS}

Return to Classrooms, Progressive Return, Return Process, Education during COVID-19, Face-to-Face Education during the Pandemic, Informed and Consensual Decisions, Shared Responsibilities, New Normal

\section{INTRODUCTION}

The phase of gradual opening in economic and social life has begun after the confinement in several regions of the world, due to the COVID-19 pandemic. This transition includes education systems. The progressive return to the classroom should solve the academic and emotional problems of the students, derived from studying at home.

The path is still covered in the fog of uncertainty but information and knowledge help to clear it. It involves a series of careful decisions to protect life as a fundamental value. Therefore, the critical variable is the dynamic of the pandemic.

Returning to the classroom, in a responsible way, implies a systematic process of diagnostic evaluation, planning, preparation, management and progressive return. This will be the way to move towards a "new normal". That will prefigure qualitative transformations of educational institutions and of the new human beings that will be formed there.

\section{FOUNDATIONS TO RETURN}

Students, teachers, parents and other institutional actors have been adapting to the home study modality. Although, the problems arising from the confinement have not been overcome and it is possible that they tend to become more acute. Educational institutions will have to continue dealing with these difficulties. Besides, they have to face the new problems that arise from the gradual return to the schools when the conditions are given.

Solving these two sets of problems requires basic conceptual references that strengthen convictions and allow us to envision viable paths to advance with safe steps. Life as the supreme value is the horizon and the main guide. The central criterion for making informed decisions is the dynamic of the pandemic. It is a process to follow with shared responsibilities in different areas and levels. The dynamic of this disease is the 
determining factor for any decision related to returning to the classroom given that life is the main value and that it is severely affected by COVID- 19 .

Epidemiologists define $\boldsymbol{R}$ as the expected number of infections (secondary cases) generated by a typical infected individual. If this occurs in a population in whicheveryone is susceptible (at the beginning of an epidemic, hence the subscript zero), we have the R0 or basic reproductive number. This indicator was explicitly defined for the first time by the epidemiologist Klauz Dietz in 1975 (Dietz, 1975). $R$ is considered to be the most important indicator for the study and monitoring of epidemics, particularly to assess the effect of control strategies that frequently have very high social and economic costs. (Rosero-Bixby, 2020, p.1)

The dynamics of the pandemic are expressed in different variables. Some of these values are conducive to starting the return to the classroom: Significant decrease in infected and deaths and a notable increase in recovered. The right moment for return is $\mathrm{R} 0<1$.

Predictive models are used by governments to decide what actions to take. Manrique \& others (2020) point out: "In the global experience and in the current pandemic, there are at least three types of responses or strategies. The first is, do not respond, the second is the mitigation strategy, and the third is the suppression strategy. " P.7

Responsibility for decisions and actions is shared by the actors at different levels. However, they are not so easy to take, given the need to reconcile the interests of different sectors of society; among them, the so-called productive sector. These decisions are prone to the political and economic models that operate in reality, and to the conceptions of development, assumed by each ruler. But, in all this, there is something unequivocal: listening to the different voices and seeking consensus in decision-making.

It is important to have a deep knowledge of the educational institution. Set an object of adaptation to be able to care for the students and other members of the educational community who initiate the return.

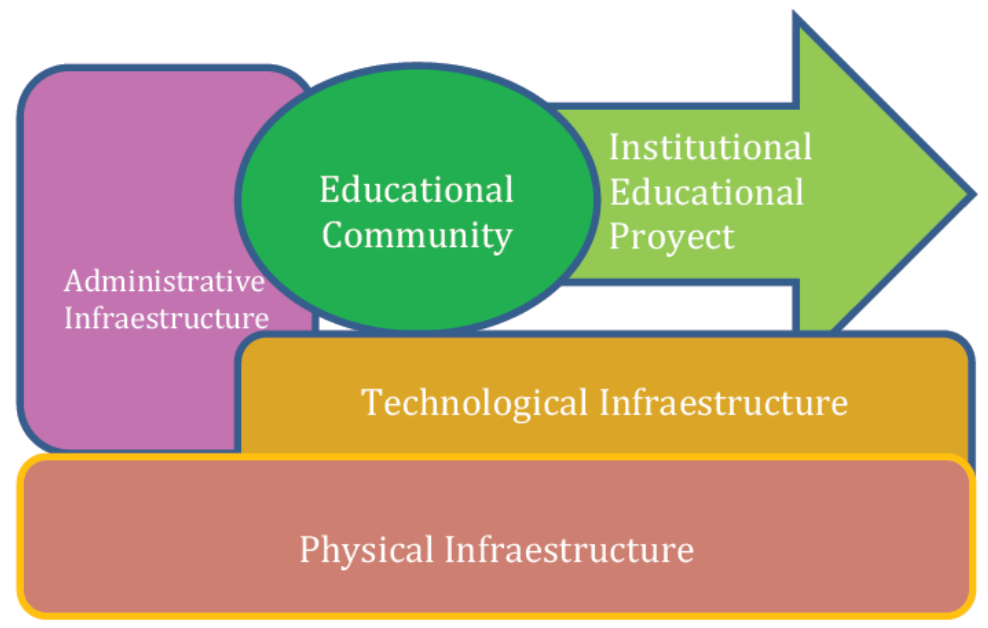

Figure 1. Structure of the educational institution

The educational institution is a group made up of a facility, technological infrastructure which work as the basis for the administrative infrastructure. With these supports, the educational community develops its institutional educational project.

The most important component of the institution is the educational community and within it the students in their several conditions, active subjects of their own learning.

\section{STRUCTURE OF THE RETURN PROCESS}

The process can be organized through the following phases: A diagnosis that allows identifying the institutional conditions in all its components. A planning phase to anticipate actions and resources. Preparation of conditions for safe and progressive return. A trial stage of what was planned and prepared in order to validate decisions and make adjustments to plans. Finally, the implementation of the gradual return, with monitoring and followup, in periods of time until reaching full face-to-face activity. 


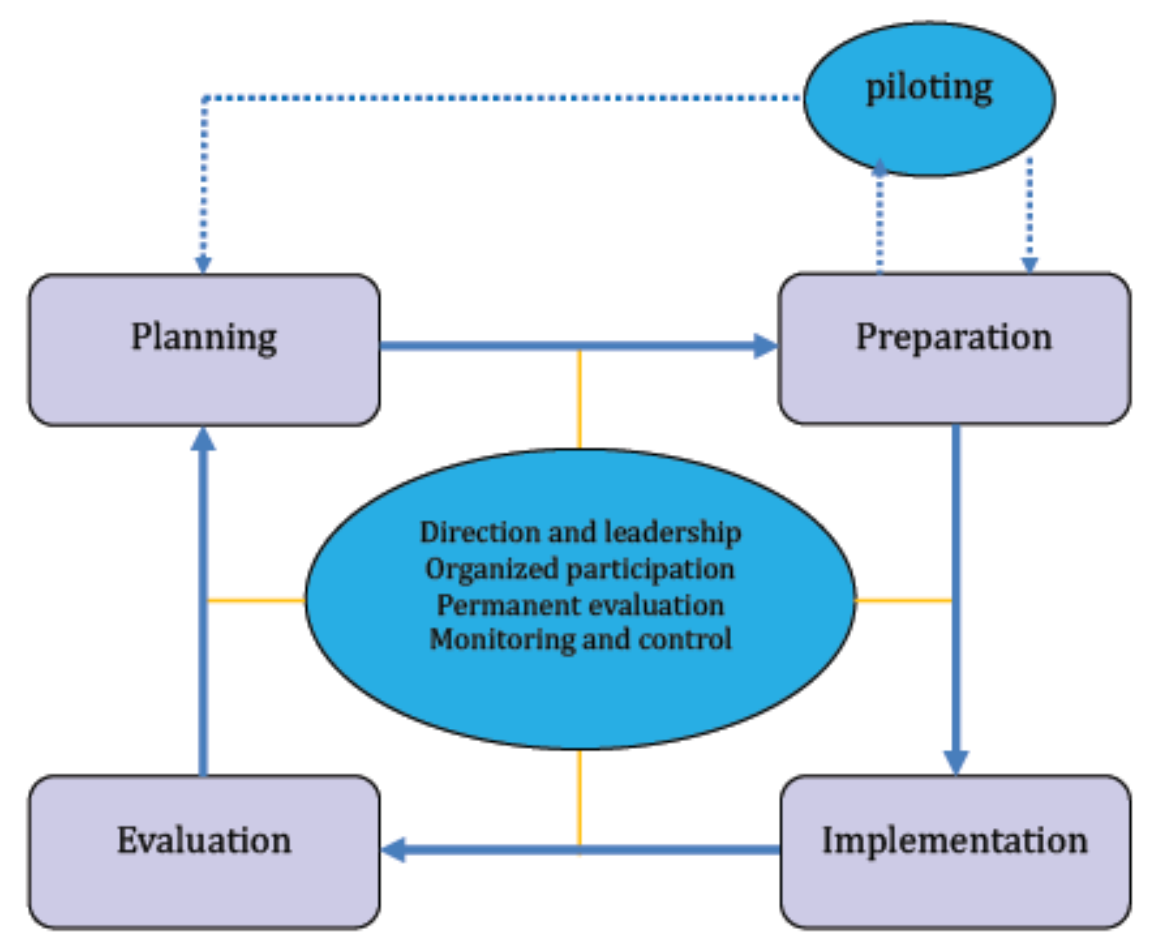

Figure 2. Phases of the transition process to the classroom

Based on the diagnostic evaluation, a meticulous planning is carried out, which is specified in the preparation of the institutional conditions. Trial proves the plan whose adjustments allow gradual implementation. Through this continuous cycle, progress is made in progressive stages of approach to the "new normal".

Return safely requires diagnosis, planning and enrollment in each of the institutional components described: educational community, physical plant, educational facilities and Institutional Education Project (PEI). And within the PEI, a comprehensive work in each of its components: administrative management, academic management, community management and the relationship with the environment.

The purpose of the diagnosis is to identify the external and internal conditions of the educational institution as a basis to determine what can be done. Externally, all those factors that affect the educational institution are identified; because they can constitute threats or opportunities. In the internal order, an institutional evaluation is carried out at the moment, to assess the achievements obtained and to try to overcome the difficulties presented during the time in which children and young people have had to study confined in their homes.

A good diagnostic evaluation allows a correct planning which aims to foresee the sequence of actions and the essential resources for the gradual return to the classrooms, when the conditions are favorable. Also, have the study at home under the best possible conditions in order to continue the formative process.

The main purpose of preparing the return to the classroom is to materialize the objective conditions and create the subjective conditions in order to guarantee the defense and preservation of the life of all the community who return. This implies the sanitation of spaces and materials, and in a special way, the assurance of biosafety practices in the institutional dynamics within the educational establishment.

The following purpose is to guarantee the pedagogical conditions to increase the levels of learning, beyond those reached at home to achieve the objectives of the curriculum and the institutional quality goals.

Piloting is a small-scale exercise to test the validity of a specific intervention model. It is a form of rational action in order to safely advance in the implementation of the model on a large scale.

The pilot test is used in innumerable contexts as a way to limit negative effects, economic losses, resources, time, etc. If the aforementioned test has positive consequences, then the project will proceed; otherwise, it will be set aside or modified to make it viable (Definicion Mx, 2014, para. 1). 
Progress is a set of transformations that concur in more evolved forms where they start. The progressive implementation, like a gradual increase in attendance is caused by a quantitative criterion, in the sense of the rhythmic increase in the number of students and teachers who return to the institution. This imaginary shows its own importance.

The duration of each stage should have been considered in the plan. However, these times may be contracted or extended, depending on the results that are obtained

\section{TOWARDS THE "NEW NORMAL"}

The progressive return to the classroom will finally reach full presence. Then, the new normal will be established where a wide range of feelings and intentions will converge, a prelude to challenges and opportunities. The new scenario will show the problems not solved before the pandemic, transformed, and possibly accumulated.

In the "new normal", the great challenge will be to overcome academic lags and move towards the achievement of new learning objectives of a renewed curriculum. It will have to be done in the midst of the material deficiencies typical of the impoverishment that the pandemic will have left many families. Hence the need to strengthen the institutional framework, initiating renewal processes in each of the components: adequate physical plant, relevant and sufficient educational facilities, modernized administrative infrastructure, cohesive educational community and updated PEI.

It will be necessary to renew educational policies for the qualification of teachers that allow deepening the appropriation of advanced information and communication technologies. The moment will be given to make institutional systems more flexible, allowing the hybridization between face-to-face and virtuality, especially for vulnerable populations, itinerant populations and for children and young people with exceptional abilities and talents.

If so, politics will be focused on restoring ecological balances, strengthening science and technology for human development, developing infrastructure for well-being and progress. Also, support people living in poverty not with the mentality of "helping" so that they remain poor but with the sense of cooperation so that they are forged as competent people, generators of their own wealth. In this sense, the vital minimum demanded by many social sectors, or the so-called guaranteed basic income will open the way to the longed for social and economic balance. Zambrano (2020), proposes the Guaranteed Basic Income, as a permanent policy, delivered to people who are unable to obtain a minimum income for life.

The foreseeable transformations will be possible to the extent that we have assimilated this experience, not only having lived it, but also having learned from it. May the memory of those who fell due to the pandemic and the pain of their families should be the force that unleashes the transformations that the current civilization requires to make human survival possible!

\section{REFERENCES}

Definición Mx. (2014). Prueba Piloto. Editorial Definición Mx. Ciudad de México. Retrieved August 6th 2020 from https://definicion.mx/prueba-piloto/

Dietz, K. (1975). Transmission and control of arbovirus diseases. Epidemiology, 104, 104- 121.

Manrique, F. \& Otros (2020). Modelo SIR de la pandemia de COVID-19 en Colombia. En: Salud Pública 22-1.9, 2020. Retrieved July 7th 2020 from http://www.scielo.org.co/pdf/rsap/v22n1/0124-0064-rsap-22-01-e185977.pdf

Rosero-Bixby, L. (2020). Matemáticas de la tasa $R$ de Covid-19 desde la demografía (documento en revisión). Retrieved from: https://ccp.ucr.ac.cr/documentos/portal/tasa-r-covid-19/R-Mate.pdf 